\title{
Cervical Dystonia Refractory to Botulinum Toxin Responding to Radiofrequency Ablation: A Case Report
}

\section{Saugat Dey (D) \\ Sayantani Ghosh (iC)}

Benefis Health System, Great Falls, MT, USA
Correspondence: Saugat Dey

Pain Management Center, Dartmouth-

Hitchcock Medical Center, 7

Timberwood Drive, Apt 230, Lebanon,

NH 03766, USA

Tel +l 2677360286

Email saugatharidwar@gmail.com
This article was published in the following Dove Press journal:

Journal of Pain Research

\begin{abstract}
A 62-year-old male diagnosed with cervical dystonia (CD) and chronic rightsided neck pain presented to the Pain Clinic after his pain and CD symptoms failed to resolve with botulinum toxin therapy. During clinical examination, right $\mathrm{C} 3-\mathrm{C} 4$ and $\mathrm{C} 4-\mathrm{C} 5$ facet arthropathy was suspected. After two sets of diagnostic right cervical, C3, C4, and C5 medial branch blocks provided $>80 \%$ pain relief; cervical radiofrequency ablation (CRFA) was performed. Post CRFA, the patient was followed for 12 months. Till the last follow-up, he was not only experiencing $90 \%$ pain relief, but also had significant improvement in his CD symptoms to the point that he no longer needed botulinum toxin and other CD-related therapy. This report suggests that large-scale research is required to postulate whether CD patients, whose symptoms are refractory to botulinum toxin, should be routinely screened for cervical facet arthropathy. This is the first reported case of improvement in CD symptoms with CRFA. This effect could be explained by the fact that certain deep cervical muscles, which are affected in $\mathrm{CD}$, are innervated by medial branch nerves.
\end{abstract}

Keywords: cervical dystonia, radiofrequency ablation, botulinum toxin, neck pain, medial branch nerves, deep neck muscles

\section{Introduction}

Dystonia has been described, by an International consensus in 2013, as a disorder which is characterized by intermittent or sustained muscle contractions causing abnormal movements and/or postures. ${ }^{1}$ Dystonia can be further classified into focal, segmental, and generalized. ${ }^{2}$ Cervical dystonia (CD) has an adult-onset, predominantly involves the neck muscles, and is the most common form of focal dystonia. ${ }^{2}$ Based on the default positioning of the neck relative to the trunk, CD patients are classified into the following types: laterocollis, retrocollis, anterocollis, and torticollis. $^{3}$ A 1988 Mayo Clinic study estimated the prevalence of CD as 8.9 per 100,000 in the US population. ${ }^{4}$ But a more recent international collaborative epidemiological study predicted the prevalence to be 20 to 4,100 cases/million. ${ }^{5}$ Apart from involuntary cervical muscle contractions causing abnormal movements and postures, pain is also frequently reported in $\mathrm{CD}$ patients. ${ }^{6} \mathrm{CD}$ patients are primarily treated with botulinum toxin injections every 12 weeks as well as physical therapy. ${ }^{7}$ Low dosages of medications including baclofen, anticholinergics, and benzodiazepine are usually well tolerated in early stages. ${ }^{2,8}$ Selective cervical denervation procedures and deep brain stimulation are surgical treatment options for CD. ${ }^{9}$ 
Cervical medial branch radiofrequency ablation (CRFA) involves thermocoagulation of the medial branches of the dorsal rami of cervical spinal nerves. ${ }^{10}$ These nerves provide sensory innervation to cervical zygapophysial joints, also known as facet joints. CRFA, though routinely used for patients with chronic neck pain, has never been reported in the published literature to relieve symptoms of $\mathrm{CD}$. In this paper, we retrospectively present a CD patient whose symptoms were not controlled by botulinum toxin and subsequently experienced significant relief with CRFA. As this was a retrospective reporting of a single patient, an Institutional Review Board review was not required. ${ }^{11}$ Although no HIPAA identifier was used in either the text of the paper or in the accompanying figure, the patient provided written informed consent for publication of the case details and the images.

\section{Case}

A 62-year-old male presented with chronic right-sided, predominantly axial, neck pain. His pain started insidiously at the age of 16 and worsened gradually over the years. At the age of 55, he was diagnosed with cervical radiculopathy and underwent $\mathrm{C} 5-\mathrm{C} 6$ anterior cervical discectomy and fusion. The surgery provided pain relief for a few weeks. However, he soon developed worsening neck pain and involuntary movements as well as neck muscle tightness. After an extensive neurological workup, the patient was diagnosed with $\mathrm{CD}$ with predominant retrocollis. He was initiated on physical therapy and oral baclofen treatment. After failing initial therapy, EMG guided botulinum toxin injections were trialed and then continued every 3 months. Initially with botulinum toxin therapy, the patient reported some improvement in his neck pain. However, soon his neck pain worsened and certain movements, especially neck extension, were associated with increased pain. This pain worsened gradually over the next 5 years and the patient was referred to the Pain Clinic.

Physical examination demonstrated cervical paraspinal tenderness and worsening pain on extension and ipsilateral rotation at the right $\mathrm{C} 3-4$ and $\mathrm{C} 4-5$ facet joints. Clinically, right $\mathrm{C} 3-\mathrm{C} 4$ and $\mathrm{C} 4-\mathrm{C} 5$ facet arthropathy was suspected. Cervical spine CT further revealed evidence of cervical spondylosis. MRI was not performed as the patient had a biventricular pacemaker and implantable cardioverter defibrillator (ICD). Subsequently, two sets of diagnostic right cervical $\mathrm{C} 3, \mathrm{C} 4$, and $\mathrm{C} 5$ medial branch blocks (MBBs) were performed under fluoroscopy per the established techniques. ${ }^{12}$ For the first block, $0.3 \mathrm{~mL}$ of $1 \%$ lidocaine was used at each level, while the second block was performed using $0.3 \mathrm{~mL}$ of $0.25 \%$ bupivacaine. The patient experienced more than $80 \%$ pain relief for the duration of the respective blocks.

Following the cervical MBBs, right cervical C3, C4, and $\mathrm{C} 5$ medial branch radiofrequency ablations were performed. As the patient had a biventricular ICD, cardiology clearance was obtained prior to the CRFA and a device representative was present on site for the entire duration of the procedure. The ICD was interrogated both pre and post procedure and a magnet was placed over the biventricular ICD during the CRFA to deactivate tachymode. The grounding pad of the radiofrequency generator was also placed on the side opposite to ICD. The procedure was performed under fluoroscopy guidance using the established technique and aseptic precautions. ${ }^{13}$ The patient was in a prone position and the skin and subcutaneous tissue at each of the three sites were anesthetized with $4 \mathrm{~mL}$ of $1 \%$ lidocaine. A 20 -gauge $100 \mathrm{~mm}$ curved tip radiofrequency cannula with a $10 \mathrm{~mm}$ active tip (Avanos Medical, Alpharetta, GA, USA) was then advanced towards the centroid of right $\mathrm{C} 4$ articular pillar. The needle position was also adjusted and verified using lateral views. Motor testing was performed at $2 \mathrm{~Hz}$ up to 2 volts and was negative for stimuli outside the immediate area of the lesion site. Then, $1 \mathrm{~mL}$ of $1 \%$ Lidocaine was injected through the cannula. The radiofrequency probe was placed through the cannula and two 90 second $80^{\circ} \mathrm{C}$ lesions were generated. The same procedure was repeated using an identical technique at the right C3 and C5 levels. Figure 1 illustrates the cannula and probe positions during the CRFA procedure in lateral fluoroscopy view.

\section{Results}

Numeric rating scale (NRS) of pain and self-reported percentage improvement of function from baseline were identified as post-procedural outcome indicators. Post CRFA, the patient experienced sustained $90 \%$ pain improvement and significant improvement in neck movements and stiffness at 1, 3, 6, and 12-month follow-up visits. Table 1 summarizes the outcome indicators at each of the follow-up visits. The patient had no complications during or after the procedure. The patient had also stopped using any pain medications post CRFA. Moreover, the patient reported significant improvement in his CD symptoms, and stopped botulinum toxin injections or any other medications to control his CD. 

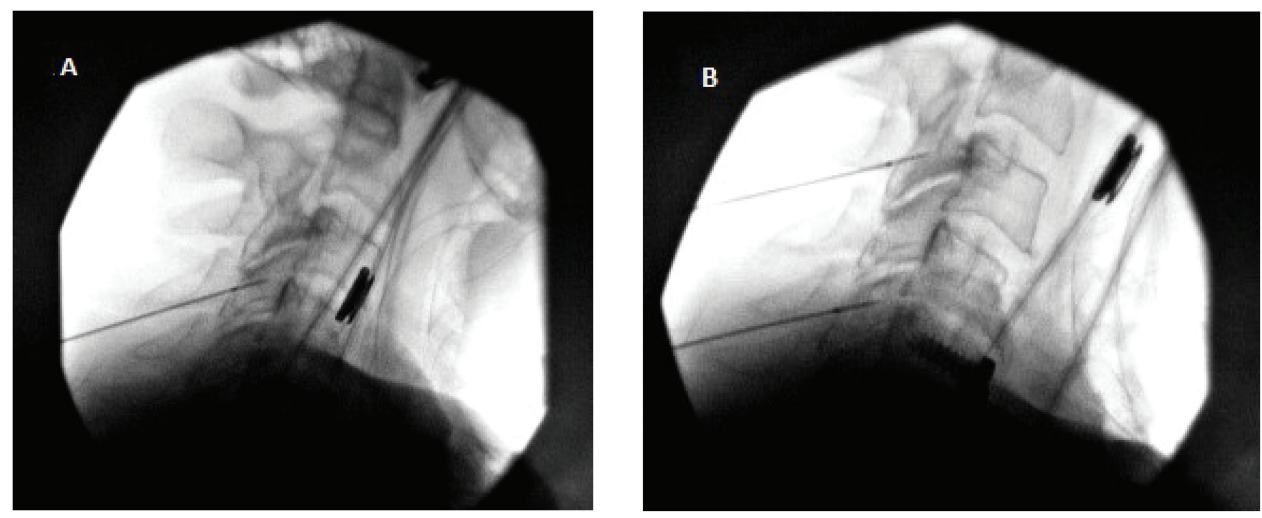

Figure I X-ray (lateral view) images illustrating the cannula and probe positions during the CRFA procedure: (A) at C4 medial branch and (B) at C3 and C5 medial branches.

\section{Discussion}

Botulinum toxin injections are the first-line therapy for $\mathrm{CD}$ patients. However, if coexisting facet arthropathy is suspected, CRFA can be an effective alternative, especially for patients whose symptoms are no longer alleviated by botulinum toxin. In patients having a prior history of spinal fusion, adjacent segment disease leading to facet arthropathy is not uncommon. ${ }^{14}$ Although imaging studies provide help in diagnosis, clinical diagnosis of facet arthropathy remains the key to managing such patients. ${ }^{10}$ Recent research considers paraspinal tenderness a better clinical indicator of facet arthropathy than the facet load test (pain on extension and ipsilateral rotation). ${ }^{15}$ Selecting the right candidate for CRFA remains another crucial concern. Diagnostic MBBs have a decisive role in predicting the success of CRFA as a 2020 study reported that CRFA is usually effective in any patient who reports $80 \%$ or more symptom relief with the diagnostic dual MBBs. ${ }^{16}$

The most interesting finding in the patient presented is that CRFA not only improved cervical facet arthropathy associated pain, but also improved his CD symptoms including muscle stiffness and involuntary neck postures. CRFA eliminated the

Table I Outcome Indicators at Follow-Up Visits

\begin{tabular}{|l|l|l|}
\hline Study Interval & $\begin{array}{l}\text { Pain } \\
\text { Numeric } \\
\text { Rating Scale }\end{array}$ & $\begin{array}{l}\text { Self-Reported } \\
\text { Function } \\
\text { Improvement from } \\
\text { Baseline }\end{array}$ \\
\hline Pre-procedural & 10 & Baseline \\
I-Month follow-up & $\mathrm{I}$ & $80 \%$ \\
3-Month follow-up & $\mathrm{I}$ & $90 \%$ \\
6-Month follow-up & $\mathrm{I}$ & $90 \%$ \\
I2-Month follow-up & $\mathrm{I}$ & $90 \%$ \\
\hline
\end{tabular}

need for continuing his every 3-month botulinum toxin injections. CRFA associated improvement of CD symptoms has not been reported in published literature yet. A potential explanation of this effect could be that cervical medial branch nerves, which originate from the dorsal rami of cervical spinal nerves, also innervate certain muscles which are commonly involved in CD. Apart from innervating the zygapophyseal joints (facet joints), medial branches innervate the deep muscles in the neck such as multifidus, semispinalis capitis, and semispinalis cervicis muscles. ${ }^{17}$ The latter two are among the muscles which are commonly affected in $\mathrm{CD}$, and are routinely targeted with both botulinum toxin and surgical modalities, such as myomectomy and denervation., ${ }^{9,18}$

\section{Conclusion}

Patients with CD symptoms refractory to botulinum toxin may be screened for facet arthropathy and considered for CRFA candidacy. Large-scale prospective trials are needed to postulate whether facet arthropathy screening should be routinely performed for $\mathrm{CD}$ refractory to botulinum toxin. CRFA can not only alleviate cervical pain, but also relieve some of the associated motor symptoms in certain CD patients. In such patients, CRFA can reduce or eliminate the need for botulinum toxin and other conventional treatment options.

\section{Disclosure}

Saugat Dey is currently affiliated with Pain Management Center, Dartmouth-Hitchcock Medical Center, Lebanon, NH, USA. The authors report no conflicts of interest in this work.

\section{References}

1. Albanese A, Bhatia K, Bressman SB, et al. Phenomenology and classification of dystonia: a consensus update. Mov Disord. 2013;28 (7):863-873. doi:10.1002/mds.25475 
2. Velickovic M, Benabou R, Brin MF. Cervical dystonia pathophysiology and treatment options. Drugs. 2001;61(13):1921-1943. doi:10.2165/00003495-200161130-00004

3. Camargo CH, Teive HA, Becker N, Baran MH, Scola RH, Werneck LC. Cervical dystonia: clinical and therapeutic features in 85 patients. Arq Neuropsiquiatr. 2008;66(1):15-21. doi:10.1590/ S0004-282X2008000100005

4. Nutt JG, Muenter MD, Aronson A, Kurland LT, Melton LJ. Epidemiology of focal and generalized dystonia in Rochester, Minnesota. Mov Disord. 1988;3(3):188-194. doi:10.1002/mds.870030302

5. Defazio G, Jankovic J, Giel JL, Papapetropoulos S. Descriptive epidemiology of cervical dystonia. Tremor Other Hyperkinet Mov. 2013;3.

6. Tomic S, Petkovic I, Pucic T, Resan B, Juric S, Rotim T. Cervical dystonia and quality of life. Acta Neurol Belg. 2016;116(4):589-592. doi:10.1007/s13760-016-0634-1

7. Hu W, Rundle-Gonzalez V, Kulkarni SJ, et al. A randomized study of botulinum toxin versus botulinum toxin plus physical therapy for treatment of cervical dystonia. Parkinsonism Relat Disord. 2019;63:195-198. doi:10.1016/j.parkreldis.2019.02.035

8. Greene P, Shale H, Fahn S. Analysis of open-label trials in torsion dystonia using high dosages of anticholinergics and other drugs. Mov Disord. 1988;3:46-60. doi:10.1002/mds.870030107

9. Wilson TJ, Spinner RJ. Selective cervical denervation for cervical dystonia: modification of the bertrand procedure. Oper Neurosurg. 2018;14(5):546-555. doi:10.1093/ons/opx147

10. Cohen SP, Huang JH, Brummett C. Facet joint pain-advances in patient selection and treatment. Nat Rev Rheumatol. 2013;9 (2):101-116. doi:10.1038/nrrheum.2012.198

11. Electronic code of federal regulations. Title $45 \rightarrow$ Subtitle A $\rightarrow$ Subchapter A $\rightarrow$ Part 46-Protection of human subjects. 2018. Available from: https://www.ecfr.gov/cgi-bin/text-idx?m=07\&d= $19 \& \mathrm{y}=2020 \& \mathrm{~cd}=20200709 \& \mathrm{sub} \mathrm{mit}=\mathrm{GO} \& \mathrm{~S} \mathrm{ID}=$ $83 \mathrm{~cd} 09 \mathrm{e} 1 \mathrm{c} 0 \mathrm{f} 5 \mathrm{c} 6937 \mathrm{~cd} 9 \mathrm{~d} 7513160 \mathrm{fc} 3 \mathrm{f} \&$ node $=p t 45.1 .46 \& \mathrm{pd}=$ 20180719\#se45.1.46_1102. Accessed July 12, 2020.
12. International Spine Intervention Society. 2013. Cervical medial branch blocks. In: Bogduk N editor, Practice Guidelines for Spinal Diagnostic and Treatment Procedures. 2nd ed. San Francisco: International Spine Intervention Society; 85-114.

13. International Spine Intervention Society. 2013. Cervical medial branch thermal radiofrequency neurotomy. In: Bogduk $\mathrm{N}$ editor, Practice Guidelines for Spinal Diagnostic and Treatment Procedures. 2nd ed. San Francisco: International Spine Intervention Society; $133-169$

14. Tobert DG, Antoci V, Patel SP, Saadat E, Bono CM. Adjacent segment disease in the cervical and lumbar spine. Clin Spine Surg. 2017;30(3):94-101. doi:10.1097/BSD.0000000000000442

15. Cohen SP, Bajwa ZH, Kraemer JJ, et al. Factors predicting success and failure for cervical facet radiofrequency denervation: a multi-center analysis. Reg Anesth Pain Med. 2007;32(6):495-503. doi:10.1016/j.rapm.2007.05.009

16. Burnham T, Conger A, Salazar F, et al. The effectiveness of cervical medial branch radiofrequency ablation for chronic facet joint syndrome in patients selected by a practical medial branch block paradigm. Pain Med. 2020. doi: $10.1093 / \mathrm{pm} / \mathrm{pnz} 358$

17. Zhang J, Tsuzuki N, Hirabayashi S, Saiki K, Fujita K. Surgical anatomy of the nerves and muscles in the posterior cervical spine: a guide for avoiding inadvertent nerve injuries during the posterior approach. Spine. 2003;28:1379-1384. doi:10.1097/01.BRS.0000067 095.75764.D3

18. Tatu L, Jost WH. Anatomy and cervical dystonia: "Dysfunction follows form". J Neural Transm. 2017;124(2):237-243. doi:10.100 7/s00702-016-1621-7
Journal of Pain Research

\section{Publish your work in this journal}

The Journal of Pain Research is an international, peer reviewed, open access, online journal that welcomes laboratory and clinical findings in the fields of pain research and the prevention and management of pain. Original research, reviews, symposium reports, hypothesis formation and commentaries are all considered for publication. The manuscript management system is completely online and includes a very quick and fair peer-review system, which is all easy to use. Visit http:// www.dovepress.com/testimonials.php to read real quotes from published authors. 